\title{
Assessment of Explicitly Stated Interval Change on Noncontrast Head CT Radiology Reports
}

\author{
(D) M. Braileanu, D. Crawford, (DS.R. Key, and D.E. Mullins
}

\begin{abstract}
BACKGROUND AND PURPOSE: Consistent and standardized reporting of interval change for certain diagnoses may improve the clinical utility of radiology reports. The purpose of this study was to assess explicitly stated interval change of various findings in noncontrast head CT reports.
\end{abstract}

\begin{abstract}
MATERIALS AND METHODS: A retrospective review was performed on successive noncontrast head CT radiology reports from the first 2 weeks of January 2014. Reports with at least 1 prior comparison CT scan were included. Reports with normal examination findings and those that made comparison with only other types of examinations (eg, MR imaging) were excluded. Descriptive and subgroup statistical analyses were performed.

RESULTS: In total, 200 patients with 230 reports and 979 radiographic findings were identified. The average interval between reports was $344.9 \pm$ 695.9 days (range, $0-3556$ days). Interval change was mentioned $67.3 \%(n=659)$ of the time for all findings $(n=979)$. Explicitly stated interval change was significantly associated with nonremote findings $(P<.001)$ and generalized statements of interval change $(P<.001)$. The proportion of interval change reported ranged from $95.3 \%$ of the time for hemorrhagic to $36.4 \%$ for soft-tissue/osseous categorizations.
\end{abstract}

CONCLUSIONS: Interval change reporting was variable, mentioned for $67.3 \%$ of noncontrast head CT report findings with a prior comparison CT scan. Structured radiology reports may improve the consistent and clear reporting of interval change for certain findings.

ABBREVIATION: IC = interval change

$\mathbf{T}$ he radiology report is essential in helping clinicians assess patient care, especially during changing treatment plans or prolonged hospital stays. ${ }^{1,2}$ Given the large amount of data primary teams have to review, careful summarization of radiographic findings provides an efficient evaluation of diagnostic abnormalities. ${ }^{3}$ Assessment of interval change (IC) through comparison with prior radiology reports may improve communication with the primary team, provide excellent patient care, and have important medicolegal implications. ${ }^{4,5}$ However, there are limited published data in the scientific literature on this topic. ${ }^{3}$ The purpose of this study was to assess explicitly stated IC, specifically for different individual findings, in noncontrast head CT radiology reports.

Received February 27, 2019; accepted after revision April 24.

From the Department of Radiology and Imaging Sciences, Emory University School of Medicine, Atlanta, Georgia.

Paper previously presented at: Annual Meeting of the American Society of Neuroradiology, May 18-23, 2019; Boston, Massachusetts.

Please address correspondence to Maria Braileanu, MD, Department of Radiology and Imaging Sciences, Emory University School of Medicine, Emory University Hospital, Suite BG23, 1364 Clifton Rd NE, Atlanta, GA 30322; e-mail: mbraile@emory. edu; @maria_braileanu

http://dx.doi.org/10.3174/ajnr.A6081

\section{MATERIALS AND METHODS}

A retrospective review was performed on all noncontrast head CT radiology reports from the first 2 weeks of January 2014. Reports from this time period were requested through our institutional datarequest system and then were successively analyzed. Studies could be from the emergency department, inpatient floors, or outpatient clinic. At our institution, many radiologists from the neuroradiology department, community radiology specialists, and emergency and trauma imaging radiology divisions interpret noncontrast head CTs. This study was institutional review board-approved.

Reports within that time period with at least 1 explicitly stated prior noncontrast head CT comparison were included. Interval change was defined as an explicit reference to the prior report and/or radiographic images. A full date (day, month, year) was required for inclusion; nonsensical dates were excluded. The accuracy of the prior dates was assumed, and we did not verify prior dates because it was outside the scope of the study. Normal examination findings, outside hospital comparisons/priors, and comparisons with other types of examinations (eg, MR imaging and/or CTA) were excluded. All reports within the 2-week period were reviewed, including repeat examinations of the same patient. If there were multiple noncontrast 


\begin{tabular}{ll}
\hline \multicolumn{1}{c}{ Finding } & \multicolumn{1}{c}{ Elaboration } \\
\hline Hemorrhage & Intraparenchymal, intraventricular, subdural, subarachnoid, extra-axial hemorrhages/suspicious collections \\
Infarct/ischemia & Transcortical, ischemia, encephalomalacia \\
Intracranial mass & Known and unknown diagnosis; including intraparenchymal, sellar, pineal, and so forth \\
Mass effect & Herniation, midline shift, diffuse edema, sulcal effacement, ventricular effacement \\
Microvascular & Chronic ischemic microvascular white matter changes, lacunar infarctions \\
Pneumocephalus & Intraparenchymal, extra-axial, intraventricular \\
Postprocedural & Craniotomy, craniectomy, ventricular catheters/drains, drains, cataract surgery, lines \\
Sinus & Acute or chronic paranasal or mastoid disease \\
Soft-tissue/osseous & Any abnormalities pertaining to these structures \\
& Exception: postsurgical or related to the sinuses \\
Ventricular caliber & Hydrocephalus, ex vacuo dilation, ventriculomegaly, prominent \\
Volume loss & Exception: effacement caused by mass effect \\
& Cortical atrophy/volume loss, both diffuse and focal \\
Other & Exception: ventriculomegaly likely secondary to volume loss \\
\hline
\end{tabular}

head CT priors, the most recent date was used. Images were not reviewed; as highly important as they are in general, the diagnostic accuracy of the reports was considered irrelevant for this study. Reports were both structured and narrative.

All radiographic findings described in the reports were collected. "Finding" was defined as a radiographic diagnosis or abnormality; a formal diagnosis was not required. For example, an unknown calcification and a pathologically proved meningioma would both be included. When appropriate, findings were grouped together (ie, bilateral lacunar infarcts versus listing each lacunar infarction separately) unless the IC was described separately in the report (ie, bilateral lacunar infarction with 1 new lacunar infarction).

All abnormalities were categorized into the following: hemorrhage, infarct/ischemia, intracranial mass, mass effect, microvascular, pneumocephalus, postprocedural, sinus, soft-tissue/osseous, ventricular caliber, volume loss, and other (Table 1). In addition, whether the finding was remote or typically chronic in the given clinical setting was collected. For example, explicitly stated "old craniotomy" was included as remote. Typically, chronic abnormalities such as microvascular ischemic changes or vascular calcifications were also considered remote. If a finding appeared unchanged after at least 6 months, it was included in this category, such as ex vacuo ventriculomegaly.

Interval change could include improvement, worsening/new, or stability of a radiographic finding as long as it was explicitly stated, similar to a previous study by Hassanpour et al. ${ }^{3}$ Ambiguous terminology (eg, "evolving," "persistent," "re-demonstrated," "again") was included as an IC but marked separately. However, for statistical analysis, these terms were included under the stable/ unchanged categorization. Chronologic terminology without a modifier was not deemed indicative of IC. For example, "old subdural hematoma" would indicate a chronic process but not necessarily an explicit IC. Similarly, "acute infarction" does not necessarily specify whether the prior examination had the finding.

Whether the IC was mentioned in the body or impression of the report was collected for all findings. Use of generalized statements was noted and assumed to apply to all diagnoses (eg, "Impression: No interval change" or "All other findings are unchanged"). However, if the statement was ambiguous or contradictory, it was not applied but collected separately. If both direct and ambiguous terminology were used in the body and impression, the most explicit IC was collected.
Descriptive and subgroup statistical analyses were performed using STATA Statistical Software: Release 14, 2015 (StataCorp, College Station, Texas). Subgroup analysis was assessed using the $\chi^{2}$ likelihood ratio test. All $P$ values were reported as 2 -sided. A $P$ value $<.05$ was statistically significant.

\section{RESULTS}

Of the 869 reports reviewed from January 1-13, 2014, two hundred thirty reports were included. In total, 200 patients with 979 radiographic findings were identified. There were 19 patients with $1-4$ additional reports within that time period. The mean age ( $n=200$ ) was $68.9 \pm 19.1$ years (range, $19-101$ years) with $56 \%$ $(n=112)$ women. The average interval between reports $(n=230)$ was $344.9 \pm 695.9$ days (range, $0-3556$ days). The time interval between reports was $<31$ days for $57.5 \%(n=563)$ of all findings $(n=979)$. In total, $42.0 \%(n=412)$ of findings were typically remote/chronic. There were 40 reports of 230 (17.4\%) with generalized statements of interval change, of which 3 were contradictory and not applied to individual findings.

Interval change was described in $67.3 \%(n=659)$ of all findings $(n=979)$ (Table 2), with $58.3 \%(n=571)$ in the body, $42.6 \%$ $(n=417)$ in the impression, and $34.2 \%(n=335)$ in both. Explicit IC $(n=659)$ was categorized as "stable" in $40.2 \%(n=394)$, "improved" in 9.8\% $(n=96)$, "worsened/new" in 9.8\% $(n=96)$, or "ambiguous" in $7.5 \%(n=73)$ of findings.

Interval change for individual findings was significantly more likely to be explicitly stated with the time between reports being $<31$ days $(P<.001)$, and with generalized statements of interval change in the report $(P<.001)$; it was less likely with remote findings $(P<.001)$ (Table 2$)$.

In subgroup analysis (Table 3), IC was significantly less likely to be explicitly stated or placed in the impression with microvascular $(P<.001, P=.01)$, sinus $(P<.001, P=.009)$, soft-tissue/ osseous $(P<.001, P<.001)$, and volume loss $(P<.001, P<.001)$ categorizations relative to all findings, respectively. Explicitly stated interval change was significantly more likely in hemorrhage $(P<.001)$, intracranial mass $(P=.02)$, and mass effect $(P=.001)$ categorizations. Mention of IC in the impression was more likely for hemorrhage $(P<.001)$ and mass effect $(P=.01)$. All other categories were not significantly different from all findings. 


\section{DISCUSSION}

The American College of Radiology Practice Parameters recommends that every report should include comparison with prior examinations when available and appropriate as part of the radiologic consultation. ${ }^{1}$ In this study, we found variable IC reporting mentioned in $67.3 \%$ of noncontrast head CT report findings with a prior examination. Whether IC was explicitly stated depended on multiple factors, including categorization of findings, chronicity of findings, and time interval between studies.

Finding categorization revealed variable application of IC. Typically, "acute" categories such as hemorrhage (95.3\%), infarct/ischemia (76.8\%), and mass effect (82.1\%) had significantly higher but not perfect IC reporting. Hemorrhage and mass effect were more likely to have explicit IC mentioned in the impression, an appropriate approach given the acute clinical significance of any change in these findings. Intracranial mass also had high IC reporting (92.9\%), which may be important for tumor monitoring and treatment planning. ${ }^{6}$ Most interesting, IC for intracranial mass was less likely to be in the impression; on a noncontrast head CT with probable advance imaging follow-up, IC of a mass may be less important than having the mass. The rate of IC reporting of pneumocephalus was only $71.4 \%$ and not significantly different from the rate for all findings, a concerning result given that pneumocephalus can be a potentially serious finding. ${ }^{7}$ The rate of explicit IC of ischemia/infarction (76.8\%) and postprocedural (69.7\%) and ventricular caliber $(72.8 \%)$ IC reporting for these categories was not significantly different from all findings, likely representing a combination of "important" (acute hydrocephalus) and "secondary" (ex vacuo dilation) findings as determined by the reading radiologist. ${ }^{8}$

Stereotypically chronic (microvascular, 50.9\%; volume loss, $47.1 \%$ ) or typically "secondary" (sinus, $43.7 \%$; soft-tissue/osseous, $36.4 \%$ ) categories were less likely to have an explicitly stated IC. Given the relative ambiguity of the American College of Radi-

Table 2: Analysis of IC for all findings $(n=979)$

\begin{tabular}{lcccc}
\hline & $\begin{array}{c}\text { Total (\%) } \\
\text { (No.) }\end{array}$ & $\begin{array}{c}\text { IC Stated } \\
(\%)(\text { No.) }\end{array}$ & $\begin{array}{c}\chi^{2} \text { Likelihood } \\
\text { Ratio }\end{array}$ & $\begin{array}{c}\chi^{2} \text { Likelihood } \\
\text { Ratio } P \text { Value }\end{array}$ \\
\hline All findings & $100 \%(979)$ & $67.3 \%(659)$ & & \\
Interval $<31$ days & $57.5 \%(563)$ & $74.1 \%(417)$ & 27.3 & $<.001^{\mathrm{a}}$ \\
Remote finding & $42.1 \%(412)$ & $52.2 \%(215)$ & 73.9 & $<.001^{\mathrm{a}}$ \\
Generalized statement & $14.1 \%(138)$ & $100 \%(138)$ & 120.0 & $<.001^{\mathrm{a}}$ \\
\hline
\end{tabular}

a Statistically significant. ology recommendations, exclusion of these findings is likely appropriate. ${ }^{2,8}$ However, in certain clinical settings, these findings, even chronic white matter microvascular ischemic changes, ${ }^{9,10}$ may be relevant to patient care. Furthermore, the ordering provider may consider a certain diagnosis more important than a radiologist does. For example, prior studies have noted inconsistent reporting of the sinuses on CT with associated dissatisfaction among otolaryngologists. ${ }^{11,12}$ Although it is likely appropriate to not mention IC for these typically chronic and "secondary" findings, careful examination of the study indication and patient presentation should always be considered before excluding IC. ${ }^{8}$

The higher rate of explicitly stated IC was significantly associated with the time interval between reports being $<31$ days $(P<$ $.001)$. Mention of IC may be important even if the interval time is $>1$ month. For example, conservative management of intracranial vascular abnormalities or surveillance after treatment may require prolonged observation and interval follow-up. ${ }^{13-15}$ Similarly, chronic findings were less likely to have explicitly stated IC $(P<.001)$. However, monitoring chronic findings for long periods may have clinical significance. For example, longitudinal volume loss is important in predicting risk and clinical outcomes in different types of dementia. ${ }^{16-18}$

Structured reporting with clear terminology may improve the reporting of IC as well as the clinical utility of radiology reports. When IC was stated in our study, it was in ambiguous terms 7.5\% of the time. Clear and standardized radiographic terminology may decrease confusion and make comparison with prior examinations easier. ${ }^{6,19}$ For our retrospective review, both structured and narrative reports were reviewed with no standardization of IC. Currently, our institution uses structured reports nearly exclusively, though IC is not included. The use of a generalized statement increased the likelihood of IC reporting in our study $(P<.001)$, and in certain respects, it may be considered a proxy for standardization. Structured radiology reports may result in improved understanding of radiographic findings and clinical utility compared with narrative reports. $^{2,6,20-22}$ Furthermore, studies have shown that clinicians may prefer standardized reports to narrative find-

Table 3: Subgroup analysis of IC for finding categorization

\begin{tabular}{|c|c|c|c|c|c|c|c|}
\hline Finding & $\begin{array}{c}\text { Total } \\
\text { (\%) (No.) }\end{array}$ & $\begin{array}{c}\text { Interval } \\
\text { Change (\%) (No.) }\end{array}$ & $\begin{array}{c}\chi^{2} \text { Likelihood } \\
\text { Ratio }\end{array}$ & $\begin{array}{l}\chi^{2} \text { Likelihood } \\
\text { Ratio } P \text { Value }\end{array}$ & $\begin{array}{c}\text { IC in the } \\
\text { Impression (\%) (No.) }\end{array}$ & $\begin{array}{c}\chi^{2} \text { Likelihood } \\
\text { Ratio }\end{array}$ & $\begin{array}{l}\chi^{2} \text { Likelihood } \\
\text { Ratio } P \text { Value }\end{array}$ \\
\hline Total & $100 \%(979)$ & $67.3 \%(659)$ & & & $42.6 \%(417)$ & & \\
\hline Hemorrhage & $13.0 \%(127)$ & $95.3 \%(121)$ & 67.5 & $<.001^{\mathrm{a}}$ & $67.7 \%(86)$ & 37.5 & $<.001^{\mathrm{a}}$ \\
\hline Infarct/ischemia & $7.0 \%(69)$ & $76.8 \%(53)$ & 3.2 & .07 & $42.0 \%(29)$ & 0.01 & .9 \\
\hline Intracranial mass & $1.4 \%(14)$ & $92.9 \%(13)$ & 5.4 & $.02^{\mathrm{a}}$ & $57.1 \%(8)$ & 1.2 & .3 \\
\hline Mass effect & $9.7 \%(95)$ & $82.1 \%(78)$ & 11.5 & $.001^{\mathrm{a}}$ & $54.7 \%(52)$ & 6.3 & $.01^{\mathrm{a}}$ \\
\hline Microvascular & $16.6 \%(163)$ & $50.9 \%(83)$ & 22.8 & $<.001^{\mathrm{a}}$ & $33.7 \%(55)$ & 6.4 & $.01^{\mathrm{a}}$ \\
\hline Pneumocephalus & $2.9 \%(28)$ & $71.4 \%(20)$ & 0.2 & .6 & $46.4 \%(13)$ & .2 & .7 \\
\hline Postprocedural & $14.8 \%(145)$ & 69.7\% (101) & 0.4 & .5 & $41.4 \%(60)$ & 0.1 & .7 \\
\hline Sinus & $5.8 \%(57)$ & $43.9 \%(25)$ & 14.1 & $<.001^{\mathrm{a}}$ & $26.3 \%(15)$ & 6.9 & $.009^{\mathrm{a}}$ \\
\hline Soft-tissue/osseous & $4.5 \%(44)$ & $36.4 \%(16)$ & 18.5 & $<.001^{\mathrm{a}}$ & $11.4 \%(5)$ & 21.5 & $<.001^{\mathrm{a}}$ \\
\hline Ventricular caliber & $11.6 \%$ (114) & $72.8 \%(83)$ & 1.8 & .2 & $50.9 \%(58)$ & 3.6 & .06 \\
\hline Volume loss & $8.7 \%(85)$ & $47.1 \%(40)$ & 16.3 & $<.001^{\mathrm{a}}$ & $24.7 \%(21)$ & 12.9 & $<.001^{\mathrm{a}}$ \\
\hline Other & $3.9 \%(38)$ & $68.4 \%(26)$ & 0.02 & .9 & $39.5 \%(15)$ & 0.2 & .7 \\
\hline
\end{tabular}

${ }^{a}$ Statistically significant. 
ings. ${ }^{6,20,21,23}$ In addition, important features are less likely to be missed on structured reports. ${ }^{20,21}$

Given our findings of overall poor reporting of IC, the higher percentage of reporting with generalized IC statements, and the literature regarding structured reporting, we propose including IC as a part of the standardized radiology report. An IC section should include options for overall no interval change, significant interval change as described in the report, or no comparable priors.

There are several limitations to this study. First, this was a retrospective study with reports being examined by multiple readers from different hospital settings; furthermore, retrospective categorization of patient location, given the dynamics of care transition at our institution, was impractical. However, all findings were statistically significant. Next, only noncontrast head CTs were included for simplification. It is assumed that similar patterns would be observed in different radiologic subspecialties and modalities. Similarly, comparisons with other modalities such as CTAs and MRIs were not included; however, this feature should not significantly bias the results because they were excluded. Next, the accuracy of every aspect of the reports was not verified. Although highly important, it was considered outside the scope of this study, which focused on how IC of individual findings is used in the report. In addition, we attempted to evaluate IC from both a radiologist's and referring clinician's perspectives. For practical purposes, basic accuracy was assumed. Finally, the definition of an explicitly stated IC in this study may be seen as overly exacting, though similar to definitions used in the literature. ${ }^{3}$ In addition, given the relative paucity of prior precedent in the scientific literature, ${ }^{3}$ our finding categorizations were arbitrary. Some of the findings we identified would not be anticipated to have changed in most settings. However, our definitions fulfilled our most important criterion: Would a clinician with no knowledge of the case be able to discern whether there was a prior study. Furthermore, the use of simple phrases like "unchanged" and "otherwise unchanged," we would argue, is straightforward for clinicians to understand and not overly demanding for radiologists to use.

\section{CONCLUSIONS}

We found variable explicit IC reporting that was mentioned for $67.3 \%$ of noncontrast head CT findings with a prior examination. The increased likelihood of IC being stated was significantly associated with the time between reports being $<31$ days $(P<.001)$, nonremote findings $(P<.001)$, and generalized statements of interval change $(P<.001)$. Explicit IC reporting also varied on the basis of finding type, ranging from $95.3 \%$ of the time for hemorrhagic to $36.4 \%$ for soft-tissue/osseous categorizations. Consistent reporting of interval change for certain diagnoses may improve the clinical utility of radiology reports. This may be achieved through the use of standardized and structured radiographic reports and terminology to improve the clear reporting of IC.

\section{REFERENCES}

1. Cynthia JS, Marks A, Leonard B, et al. ACR practice parameter for communication of diagnostic imaging findings. https://www. acr.org/-/media/ACR/Files/Practice-Parameters/Communication Diag.pdf. Accessed February 27, 2019

2. Ganeshan D, Duong PAT, Probyn L, et al. Structured reporting in radiology. Acad Radiol 2018;25:66-73 CrossRef Medline
3. Hassanpour S, Bay G, Langlotz CP. Characterization of change and significance for clinical findings in radiology reports through natural language processing. J Digit Imaging 2017;30:314-22 CrossRef Medline

4. Berlin L. Comparing new radiographs with those obtained previously. Am J Roentgenol 1999;172:3-6 CrossRef Medline

5. Wallis $\mathrm{A}, \mathrm{McC}$ coubrie $\mathrm{P}$. The radiology report: are we getting the message across? Clin Radiol 2011;66:1015-22 CrossRef Medline

6. Gore A, Hoch MJ, Shu HG, et al. Institutional implementation of a structured reporting system: our experience with the brain tumor reporting and data system. Acad Radiol 2019 Jan 17. [Epub ahead of print] CrossRef Medline

7. Cunqueiro A, Scheinfeld MH. Causes of pneumocephalus and when to be concerned about it. Emerg Radiol 2018;25:331-40 CrossRef Medline

8. Pandharipande PV, Herts BR, Gore RM, et al. Rethinking normal: benefits and risks of not reporting harmless incidental findings. J Am Coll Radiol 2016;13:764-67 CrossRef Medline

9. Geerlings MI, Appelman AP, Vincken KL, et al; SMART Study Group. Association of white matter lesions and lacunar infarcts with executive functioning: the SMART-MR study. Am J Epidemiol 2009;170: 1147-55 CrossRef Medline

10. Xiong YY, Mok V. Age-related white matter changes. J Aging Res 2011;2011:617927 CrossRef Medline

11. Deutschmann MW, Yeung J, Bosch M, et al. Radiologic reporting for paranasal sinus computed tomography: a multi-institutional review of content and consistency. Laryngoscope 2013;123:1100-05 CrossRef Medline

12. Becker SS, O'Malley BB. Evaluation of sinus computed tomography scans: a collaborative approach between radiology and otolaryngology. Curr Opin Otolaryngol Head Neck Surg 2013;21:69-73 CrossRef Medline

13. Yang W, Wei Z, Wang JY, et al. Long-term outcomes of patients with giant intracranial arteriovenous malformations. Neurosurgery 2016;79:116-24 CrossRef Medline

14. Paul AR, Colby GP, Huang J, et al. Selection of treatment modalities or observation of dural arteriovenous fistulas. Neurosurg Clin N Am 2012;23:77-85 CrossRef Medline

15. Sorenson TJ, Brinjikji W, Bortolotti C, et al. Recurrent brain arteriovenous malformations (AVMs): a systematic review. World Neurosurg 2018;116:e856-66 CrossRef Medline

16. Reiter K, Nielson KA, Durgerian S, et al. Five-year longitudinal brain volume change in healthy elders at genetic risk for Alzheimer's disease. J Alzheimers Dis 2017;55:1363-77 CrossRef Medline

17. Okonkwo OC, Alosco ML, Jerskey BA, et al; Alzheimer's Disease Neuroimaging Initiative. Cerebral atrophy, apolipoprotein E varepsilon4, and rate of decline in everyday function among patients with amnestic mild cognitive impairment. Alzheimers Dement 2010;6: 404-11 CrossRef Medline

18. Nedelska Z, Ferman TJ, Boeve BF, et al. Pattern of brain atrophy rates in autopsy-confirmed dementia with Lewy bodies. Neurobiol Aging 2015;36:452-61 CrossRef Medline

19. European Society of Radiology (ESR). ESR paper on structured reporting in radiology. Insights Imaging 2018;9:1-7 CrossRef Medline

20. Franconeri A, Fang J, Carney B, et al. Structured vs narrative reporting of pelvic MRI for fibroids: clarity and impact on treatment planning. Eur Radiol 2018;28:3009-17 CrossRef Medline

21. Tuncyurek O, Garces-Descovich A, Jaramillo-Cardoso A, et al. Structured versus narrative reporting of pelvic MRI in perianal fistulizing disease: impact on clarity, completeness, and surgical planning. Abdom Radiol (NY) 2019;44:811-20 CrossRef Medline

22. Bosmans JML, Weyler JJ, Parizel PM. Structure and content of radiology reports, a quantitative and qualitative study in eight medical centers. Eur J Radiol 2009;72:354-58 CrossRef Medline

23. Park SB, Kim MJ, Ko Y, et al. Structured reporting versus free-text reporting for appendiceal computed tomography in adolescents and young adults: preference survey of 594 referring physicians, surgeons, and radiologists from 20 hospitals. Korean J Radiol 2019; 20:246-55 CrossRef Medline 